\title{
8. Climate change in Vietnam Relations between government and media in the period 2000-2013
}

\begin{abstract}
Vietnam is fifth in the hierarchy of countries likely to be severely impacted by climate change. Since 2007 there has been a major expansion of reporting and discussion of this issue in Vietnamese news media. This article reports on a research study of climate change coverage from 2000 to 2013 in four major news outlets: Vietnam Television (VTV), Tuoi Tre newspaper, Nhan Dan newspaper and VnExpress. It found considerable variation in the content and temporal spread of coverage, but also some interesting commonalities, in particular an unusually prominent role for NGOs as sources. There is currently a unity of purpose in the Vietnamese government's approach to this issue. In other environmental issues, the major factor affecting government latitude for independent reporting has been the unity or conflict within government on the matter. Where there has been no conflict there has been considerable latitude for journalists to take initiatives in independent reporting, expand the field of media independence and in the process develop their own capital and professional capacities. Thus far in climate change reporting journalists have not taken advantage of this opportunity, but if the scientific predictions of catastrophic impacts are valid, the social, economic and political effects will be major, posing strong challenges to Vietnamese journalists.
\end{abstract}

Keywords: case studies, climate change, climate change adaptation, environmental reporting, independent reporting, journalism, media freedom, newspapers, Vietnam

\section{BINH DUONG PHAM and CHRIS NASH \\ Monash University, Melbourne}

\section{Introduction}

LIMATE change, with associated extreme weather events and rising sea levels, is widely recognised as a significant global issue for the 21 st century (CCBC, 2010, p. 5). In Vietnam, it poses very specific and complex problems. Vietnam has more than 70 percent of its population working in agriculture, mostly on the low-lying coastal plains and major river deltas. The country is going through Doi Moi (translated as 'renovation' in English) with major economic development goals and rapid growth in GDP, making it very challenging to protect the environment at the same time. NGOs, both national and international, have 
been playing a signficant public role which is unusual in this communist state. The government has been encouraging reporting on the issue by journalists to promote the success of its climate change awareness campaign.

The government and NGOs are therefore key players in the field of environmental journalism on climate change: their roles as sources are significant and dominant. However, the policies and projects pursued by the government have many problems and limitations with respect to climate change, and these are largely unreported by journalists. Media coverage mostly responds to the government and NGOs' articulated concerns, and its content is mainly based on their information without further independent investigation. There are limitations in the capacity and understanding of journalists and journalistic institutions regarding the domestic climate change context. Analysis of climate change issues would be considerably more complicated if it were to consider the implications for political-economic development.

It is clear that the media have an important role in raising people's awareness of climate change and policy. At this time, most of the discussions in the media are descriptive and have not analysed or evaluated government policies. For this to happen, it is necessary for journalists to accumulate knowledge and standing (capital in Bourdieu's terms) to become experts in the environmental field. On the one hand, such capital helps the media to become more efficient and useful to the community in the dissemination of information. On the other hand, it expands the capacity of the media to accumulate heteronomous capital (that is, capital from non-media fields of knowledge), which increases the position and power of Vietnamese media. Climate change is extremely significant in the context of Vietnam because it will become the biggest challenge for development; if journalists develop more environmental knowledge capital, then communication between the NGOs, government and media could become much more complex and precipitate significant changes in the relationship among stakeholders.

\section{Field theory}

In order to explore the interactions that occur in the relationship between the media and the government fields we use broadly Bourdieusian field theory (Bourdieu \& Wacquant, 1992) as the theoretical basis. Bourdieu suggests three key concepts - field, capital and habitus - to explain the structure and nature of social relationships. Boundaries or parameters or limits of a field are created by the activities and reactions of the participants within the field (Webb et al., 2002, p. 184). However, the players' activities must be framed within the standards and values of fields. For our purposes in this research, media content analysis may demonstrate how Bourdieu's conceptualisation of 'position-taking' can clarify the different role of each stakeholder and their interaction. There are various stakeholders: the government, the media, NGOs and business enterprises. At the 
same time as they are engaging in the response to climate change field, they are operating in their own fields such as the political field, journalistic field, NGOs field, economic field, social field and environmental field. Each field therefore accommodates the participation of players from other fields with different rules and boundaries. Since the opening up to a market economy, the power of the government has not been maintained in the same manner as earlier, and this affects the position and relationship of the players. It will become clear that these are very complex, dynamic and multi-dimensional relationships. For Bourdieu, orthodox and heterodox are two basic types of positions that a player can adopt with respect to the configuration of power relations in a field (Bourdieu \& Wacquant, 1992, p. 100). Because of the changes taking place in the media field in Vietnam, the orthodox/heterodox descriptors are unstable, but they can help to explain the shifting power relationship between the media and the government in the climate change case.

Capital enables the exercise of power but only through activity in a field. Capital in the journalism field includes the level of knowledge of the journalist about a specialised field (Bourdieu \& Wacquant 1992: 101), as well as the more generalised professional ability to explore problems and take appropriate action to produce reports. Journalists need dual capital because they work in the symbolic field in producing media, but do that by observing and reporting on other fields. In order to do their work, journalists need autonomous capital (for their own field) and heteronomous capital (for the different field being reported about). Above the level of the individual journalist, the form of capital in media institutions varies according to economic-cultural factors including sources of income, target audiences, relationships with stakeholders, and so forth.

The third important factor in Bourdieu's field theory is habitus (Bourdieu, 1990, p. 52), which is a socialised subjectivity and is the expression of capital in the field (Bourdieu \& Wacquant, 1992, p. 126). This is central to Bourdieu's thought. Habitus can be characterised as a 'way of being in the world' and helps enable the reproduction of practice in a field. For journalists, Bourdieu's concept of habitus is a way of theorising news values, news sense and journalism practice for this study (Nash, 2016, c. 6). Journalists need habitus to operate in both their own profesional field and the field about which they are reporting, which derives from the two sorts of capital discussed above. Habitus manifests the capacity to analyse and explain the situation in a field, the power relations that created the developments at a certain time and the potential future developments that constitute newsworthiness. Habitus helps a journalist meet the professional standards to publish the report on behalf of their news organisations. Habitus also identifies the processes signifying shifts in relationship between the media and the government, because journalists need to understand those shifting processes in order to be able to perform their professional duties. 
To summarise, Bourdieu's field theory provides a relevant framework for the methodology of this study in order to clarify the relationship between the political field and the journalistic field. The relationship of journalists to sources can be hypothesised by the three interlinked concepts of field, capital and habitus. In this study we examine these relationships and interactions with respect to the reporting of climate change in Vietnam, which was part of a larger doctoral research project examining four case studies with respect to environmental journalism in Vietnam.

Bourdieu (1998, p. 53) in discussing French broadcasting makes an important point about the changing characteristics of the journalism field in response to the contextual shift from public sector to commercial broadcasting. The application of this insight to Vietnam is relevant but different because of the local context of a one party state. Under Marxism-Leninism, the media is the voice and the arm of the party, but in Vietnam a commercial element is being added to the mix. Whereas in a Marxist-Leninist political structure the party intervenes in or controls the media, in a capitalist society it is private enterprise which funds media through advertising, and therefore potentially influences both the media and the government. This then creates a very complex situation for Vietnam.

Development journalism ideology adds another element to the mix, because it posits a close relationship between the media and the government in presenting and achieving development goals. Although the political field in each country (the government, political regime, law enforcement authorities) influences the journalism field (television, radio, newspapers, digital media) at different levels depending on the prevailing political cultures, even in the most constrained context journalism is still clearly a distinct field and has an impact on the other fields via its power of information for readers and audiences.

Bourdieu's theory of fields enables the conduct of field analyses in media reporting, including the role of sources, subjects and themes. At the same time, it encompasses the interaction between the journalism field and other fields, particularly the political field (Bourdieu and Wacquant, 1992, p. 98). Objective relationships linking the participants are the key to understanding the nature of any given social reality, so it is important to look at each field's components to understand the relationship between the media and the government (Bourdieu \& Wacquant, 1992, pp. 96-97). For example, policies, documents, regulatory frameworks and so forth play important roles in institutions.

This research conducts a source and content analysis of the reporting of climate change, and compares that reporting to official and independent (corporate and NGO) documentation on relevant policy and practice. It shows the similarities and differences between stakeholders, what their concerns are, and also analyses their interactions and conflicts. It can reveal the ways in which various sectoral interests are represented and the issues characterised by journalism. This includes 
evidence of responses in one field to pressure in other fields. For example, the government responds to media reports, business enterprises respond to government actions, media responds to business enterprises and government actions, and media outlets respond to each other. The adequacy of the policy, practice and responses by government and enterprises are mutually calibrated against each other and against the journalistic coverage.

\section{Methodology}

This research (Pham, 2017) involves an analysis and evaluation of environmental journalism relevant to climate change in four media outlets (three newspapers and one television national network) in Vietnam in the period 2000-2013.

The four media outlets are:

- Vietnam Television (VTV). This is the national broadcaster of Vietnam.

- VnExpress. This is the first and most popular online newspaper in Vietnam (commenced February 26, 2001, with no hardcopy version).

- Tuoi Tre newspaper. Tuoi Tre newspaper has grown to become one of the largest and most independent newspapers in the country.

- Nhan Dan newspaper. This is the official newspaper of the Communist Party of Vietnam.

This media study involves both quantitative and qualitative elements:

- Quantitative: analysis of content (genre, length/duration, date of publication, sources and their organisational affiliations)

- Qualitative: Close reading of significant reports (keywords) to analyse the characteristics of content in its environmental, social, economic, public health and political dimensions.

By 'triangulating' the positional documentation from the various stakeholders with the media reporting, the research produces a field analysis of the contemporary relationships within climate change in Vietnam among the government, the economic sector, the NGOs and the media. This analysis should enable some observations about the contemporary interactions and relationships between fields. It should be noted that there is not a system of 'star journalists' in Vietnam. Therefore, we are not looking at the work of individual journalists, but focusing on the output overall. Nor are we looking at the issue of conflict between journalists and their organisation. All the evidence suggests that editors and journalists are generally working together and there is no evidence of significant conflict within media organisations.

\section{Climate change in Vietnam}

According to research by UNDP, Vietnam is one of five developing countries that are most affected by climate change. Since 1990 the country has suffered from six or seven major storms and many other natural disasters each year, 
causing the death of 457 people and economic damage of USD 1.9 billion, equivalent to 1.3 percent of GDP (Huong et al., 2009, p. 157). According to scientists (RECOFTC, 2014, p. 9), by 2100 the average temperature in Vietnam could reach 30 degrees Celsius (the current average temperature is 24 degrees Celsius) and the sea level could rise by one metre. Research by other scholars (Thuy et al, 2012, p. 2) shows that climate change has already been causing serious consequences for Vietnam, particularly in agriculture which contributes about 21 percent of GDP (OXFAM, 2014, p. 3; World Bank, 2011, pp. 2-11).

\section{The context}

Climate change also has significant impacts on aquaculture and fisheries, which contribute about four percent of Vietnam's GDP (Vien, 2011, p. 17; Reid, 2008 , p. 3). High rates of deforestation have exacerbated climate change impacts through the loss of the carbon sequestration capacity of forests (DARA, 2012, p. 223). Local communities are particularly dependent on forest products for meeting basic needs, through both agriculture and illegal logging. Climate change is expected to impact on human health, as temperature rise is a precondition for the development of certain viruses and diseases, including malaria and dengue fever. Natural disasters and rising sea levels also threaten people's lives and destroy the infrastructure system, exacerbating existing levels of vulnerability. It could lead to crises involving the largest migrations in history (McMichael, et al., 2003, p. 106). It is clear that climate change has the potential to be a most devastating environmental challenge for Vietnam, impacting on economic goals and the sustainable development of the country, including poverty reduction.

\section{Public awareness}

As a developing country, Vietnam in the transitional period has witnessed mass migration from rural to urban areas and between rural areas of people looking for work. About 70 percent of people are still living in rural areas (World Bank, 2014 , p. 2) and two-thirds of these are engaging in agriculture and fisheries. Thirty years after the start of Doi Moi, many people's lives have improved. The poor and very poor are still likely to live in rural areas, including the Far North, Central Coast and MeKong Delta. Most of them are ethnic minorities.

Across Vietnam people have experienced changes in climate via unpredictable extremes of hot and cold temperatures. Extreme weather events have created problems in many areas. According to a report of the BBC Media Action (Copsey et al., 2013, p. 11), 85 per cent of Vietnamese expressed concerns about how their health was affected by changes in environment and climate, although they were less worried about fresh water, food and electricity problems. Flooding has occurred more frequently in Ho Chi Minh City and directly impacted on people's lives. In general, the public can see the obvious changes in weather. According to a report of the Australian Red Cross Vietnam (Sterrett, 2015, p. 29), more than 
70 percent of interviewees showed an increase in knowledge of climate change and believed that climate change is happening. However, more than 20 percent reported that they had not heard of climate change and they did not think climate change could occur. Most of the people could name an action to adapt to climate change (Sterrett, 2015, p. 29).

\section{The government}

\section{Vietnamese legal framework on climate change}

In recent years, the policy-making bodies and the leaders of Vietnam have changed their perceptions about climate change issues. Climate change is now considered one of the most serious challenges that Vietnam is facing today. A resolution of the 11th Congress of the Communist Party of Vietnam (CPV, 2011, pp. 4-6) concluded that responding to climate change would be prioritised over the next decade.

The government is gradually improving the legal framework on climate change, disaster risk reduction, cleaner production and energy. In 2007, it published a National Strategy on Prevention and Disaster Reduction to 2020, and followed this in 2008 with the National Target Programme to Respond to Climate Change, and Decision 380/QD-TTG on the pilot payments for forest environmental services. In 2011, it established a National Strategy on Climate Change, and since 2012 a succession of green growth strategies, including low-carbon growth, as well as the handling of environmental issues, a National programme on REDD + for forest protection and targeted mitigation programmes in industry and agriculture.

\section{Vietnam's efforts in international negotiations on climate change}

Vietnam participates in the global effort to curb climate change through the promotion of important mitigation policies. The Vietnamese government considers the Convention of the United Nations Framework on Climate Change (UNFCCC) and the Kyoto Protocol as the main legal framework to address climate change (Prime Minister, 2008, pp. 1-2). In terms of implementation, in the 1990s it became party to the UNFCCC, the Montreal Protocol on Substances that Deplete the Ozone Layer, the London Convention and the Copenhagen Convention, in 2002 the Kyoto Protocol, COP13 in Bali in 2007 and all subsequent COP events, and in 2009 the United Nations Collaborative Programme on Reducing Emissions from Deforestation and Forest Degradation in Developing Countries (UN-REDD).

The government's development of the Support Programme to Respond to Climate Change (SP-RCC) has created a forum to share policies among government agencies and the international development partners on issues related to climate change in Vietnam (MONRE, 2012, p. 3). The programme is responsible 
for supporting the implementation of important national policy on climate change through mitigation (energy efficiency, renewable energy, forest conservation, waste management and agricultural policy), adaptation (water resources, coastal zone management, natural resources, infrastructure including transportation, health and agriculture) and an interdisciplinary approach through functional integration, financial mechanisms and awareness raising. Over the period 20092014 , the development partners of SP-RCC have contributed US\$873 million to the SP-RCC programmes (MONRE, 2012, p. 6)).

There are other cooperation programmes of the government of Vietnam which aim to:

- Enhance sustainable economic development and low emissions;

- Improve investment in clean energy and energy efficiency in order to enhance energy security, limit greenhouse gas emissions, improve air quality and promote economic growth;

- Reduce emissions through enhanced alternative initiatives such as Reducing Emissions from Deforestation and Forest Degradation (REDD +), Payment for Environmental Forest Services and the Alternative Livelihood Options; and

- Strengthen the resilience of urban areas and rural areas to the impacts of climate change and disaster risk mitigation. (USAID, 2015, p. 3)

\section{NGO engagement}

The Network of NGOs in Vietnam and Climate Change (VNGO \& CC) was founded in 2008. Today, VNGO \& CC has 110 member organisations and plays a huge role in combating climate change in Vietnam.

According to Reid et al. (2012), NGOs in Vietnam have been actively involved in:

- Developing, funding and implementing important climate change programmes, both in adaptation and mitigation;

- Cooperating with the government in the development of climate change policies and plans; and

- Conducting study and projects on climate change.

The Climate Change Working Group (CCWG) since 2008 includes domestic NGOs and international NGOs (Oxfam, CARE, RECOFTC, CRS, SNV, EMW, WWF, Challenge to Change and SRD). CCWG purposes are:

- Sharing ideas and knowledge of NGOs on climate change;

- Developing policies on climate change and developing the relationship between NGOs and policy-makers; and

- Developing capacity of NGOs

It is clear from the activities of these networks and their members that NGOs, in particular international ones, have a large influence on climate change policy and action in Vietnam, to an unprecedented degree for this strongly nationalist state. This is evident in their role as sources for journalists. 


\section{Media coverage of climate change}

The numbers of climate change reports in the selected news organisations over the period 2000 to 2012 are as follows: VTV_-146; Nhan Dan newspaper-476; Tuoi Tre newspaper-454; Vn Express-30. Among these, 476 out of 1106 articles on climate change were international, while 630 were national and sub-national. The scale of media discussion shifted over time: before 2007 the media discussed the issues at an international level only, but since 2008 more national and sub-national discussion has been included. Specifically, there were large increases associated with the participation of Vietnam in COP13 in Bali and particularly COP15 in Copenhagen in 2009, and this created a forum for politicians, policy makers and leading officials. However, the media publicity without analysis of the position of the Vietnamese government in COP15 was still dominant in the coverage. As Copsey et al. (2013, p. 37) suggested, journalists in Vietnam needed to have more information and knowledge (capital) in order to effectively discuss climate change in the national socio-political context.

The media showed a swift transition from mainly reporting international climate change before 2007 to national activities afterwards, which can in part be attributed to massively increased attention internationally to COP 15 in Copenhagen and afterwards, and collaterally in response to the increasing range of government and NGO interventions cited above.

Table 1 details the spread of reports on climate change for the four mastheads over time, showing a cascading and spreading coverage.

\begin{tabular}{|c|c|c|c|c|}
\hline \multicolumn{6}{|l|}{ Table 1: Media reports in each year } \\
\hline Year & VTV & $\begin{array}{c}\text { Nhan Dan } \\
\text { Newspaper }\end{array}$ & $\begin{array}{c}\text { Tuoi Tre } \\
\text { Newspaper }\end{array}$ & VnExpress \\
\hline $19 / 1 / 2000$ & 1 & 0 & 0 & 0 \\
\hline 2001 & 3 & 0 & 0 & 0 \\
\hline 2003 & 1 & 0 & 1 & 0 \\
\hline 2004 & 0 & 1 & 2 & 0 \\
\hline 2005 & 2 & 2 & 3 & 0 \\
\hline 2006 & 1 & 4 & 6 & 0 \\
\hline 2007 & 15 & 16 & 18 & 0 \\
\hline 2008 & 12 & 36 & 33 & 1 \\
\hline 2009 & 35 & 180 & 165 & 2 \\
\hline 2010 & 26 & 112 & 1105 & 7 \\
\hline 2011 & 35 & 69 & 72 & 12 \\
\hline 2012 & 15 & 56 & 49 & 8 \\
\hline
\end{tabular}


VTV had the earliest reports, and they focused on information about the Climate Change Conferences of the United Nations and the Kyoto Protocol in the early 2000s (VTV, 2000). VTV was the only media agency that reported on climate change during this period.

Climate change has been more widely mentioned in Vietnamese media since 2007. According to Thuy $(2012$, p. 7), the media began to report on climate change when they realised the importance of climate change in the global debate at COP13 in 2007. Poor foreign language skills and limited understanding about environmental issues were identified as the cause of the lack of reporting on climate change in Vietnam before then. Since then, the number of stories on climate change has increased significantly. Dung (2008, p. 5) also suggested that the increasing number of articles could be due to the fact that the MONRE had been more active in the dissemination of information on climate change, and the leadership of the newspapers was more supportive of the work of environmental journalism.

\section{Media themes, subjects and sources}

\section{Story themes}

We coded stories according to the general narrative themes, to reveal the order of preference for themes in the media coverage. The more popular themes demonstrate the close relationship between reportage and the government's activites and priorities. Out of the stories, 59 percent reported on global climate change topics, 31 percent provided information about government actions, 5 percent of the stories reported stakeholders' proposed solutions to mitigate and adapt to climate change. Only a small number of media reports focused on health and the legal framework. There were no media-generated stories about climate change; that is to say, the Vietnamese news media did not take any initiatives to report stories on climate change, but deferred the story initiation process to mainly government and NGOs. So while climate change was certainly becoming a major topic for Vietnamese media, it was very difficult for the media to cover the issue independently in the context of their limited understanding and knowledge about this issue.

\section{Story subjects}

Subjects are the actual events that occasion the news reports, such as a policy announcement, market event, environmental problem, etc. and the choice of subject area influences the frame within which the event will be presented. Table 2 collates the character of these reports into groupings to illustrate how the media organises its climate change discussion in the context of Vietnam.

All media agencies had a majority of stories reporting on subjects of politics and policy-making. Tuoi Tre newspaper and VnExpress had a similar interest in 


\begin{tabular}{|l|c|c|c|c|}
\hline \multicolumn{3}{|c|}{ Table 2: Subjects mentioned in each media organisation } \\
\hline Subjects & VTV & $\begin{array}{l}\text { Nhan Dan } \\
\text { Newspaper }\end{array}$ & $\begin{array}{l}\text { Tuoi Tre } \\
\text { Newspaper }\end{array}$ & VnExpress \\
\hline Politics and policy & $89 \%$ & $75 \%$ & $57 \%$ & $40 \%$ \\
\hline Economy and market & $4 \%$ & $15 \%$ & $18 \%$ & $10 \%$ \\
\hline Environmental issues & $6 \%$ & $6 \%$ & $16 \%$ & $30 \%$ \\
\hline Governance situation & $0 \%$ & Less than $1 \%$ & $2 \%$ & $0 \%$ \\
\hline Health & Less than $1 \%$ & $2 \%$ & $3 \%$ & $0 \%$ \\
\hline Science & $0 \%$ & Less than $1 \%$ & $2 \%$ & $10 \%$ \\
\hline Culture & $0 \%$ & $0 \%$ & $0 \%$ & $0 \%$ \\
\hline Society & $0 \%$ & $0 \%$ & $0 \%$ & $0 \%$ \\
\hline Other & Less than $1 \%$ & $1 \%$ & $2 \%$ & $10 \%$ \\
\hline
\end{tabular}

economic and market subjects. VnExpress had only three articles on this subject and VTV had six reports (4 percent) on this subject. VTV and VnExpress each had nine articles on environmental issues. Nhan Dan newspaper had 28 articles (6 percent) on this subject and Tuoi Tre newspaper showed a major interest with 73 articles (16 percent) on this subject. Only Tuoi Tre newspaper and Nhan Dan newspaper published discussion about the governance situation: Tuoi Tre newspaper had nine articles ( 2 percent) and Nhan Dan newspaper had two articles. One in ten articles of Nhan Dan newspaper and Tuoi Tre newspaper focused on health, while VTV had only one report on this subject. Another nine articles in Tuoi Tre newspaper discussed science subjects, while Nhan Dan newspaper and VnExpress had three articles on this subject. Culture and society subjects were not mentioned in any media reports. A small number of articles discussed other subjects, such as conjecture about and the assessment of future climate change.

\section{News sources}

The source of information is the decisive factor contributing to the quality of the content of stories and the authority of the claims for truth made in the stories. Sources also contribute strongly to narrative themes and subjects in media stories. The importance of sources guides the activities of journalists in the story, including source selection, source position and source editing. It can also bring multiple voices to media stories. Every source in the selected stories was coded and then collated into groups, as shown in Table 3.

Six in ten stories quoted government representatives, who were clearly the key sources of information for the media. International sources and NGOs are also significant sources on climate change. As well, journalists acknowledge workshops and business enterprises as important and useful sources of climate change information. Although Thayer $(2009$, p. 20) posed the challenge for press 


\begin{tabular}{|l|c|}
\hline \multicolumn{2}{|l|}{ Table 3: Sources in media stories } \\
\hline Stories Quoted Sources & Percentage \\
\hline Workshops & $7 \%$ \\
\hline International sources & $12 \%$ \\
\hline Government representatives & $58 \%$ \\
\hline Business enterprises & $2 \%$ \\
\hline Non-governmental organisations & $17 \%$ \\
\hline Local people and readers & $3 \%$ \\
\hline Others & Less than $1 \%$ \\
\hline
\end{tabular}

freedom in Vietnam that government representatives are the key sources of information for the media, it is significant that Vietnamese journalists consider other organisational bodies and even local people and readers as important sources of climate change information.

Most of the media stories on climate change were news items (150-450 words) and news briefs (100-150 words). One in 30 stories were features of 1,000 to 1,500 words, focusing on global climate change or with quotes from international media. There were only a few articles over 2,000 words, and they were in-depth features. The longer reports provided extensive information on climate change as a global issue and gave forecasts at an international level. This begged the question of climate change impacts at a national level: the lack of national climate change information creates problems for the political and public understanding of the local implications of the issue, as well of course for the capacity of journalists to produce locally meaningful reports.

Most of the climate change reports were posted in the news or the environment section of all the media agencies. Reports on government activities always appeared on the front page or equivalent position of all the media publications. Other climate change stories were printed on pages 3,5 and 6-in the News, Environment, Economy or International sections.

\section{Discussion and conclusion}

This research was part of a larger doctoral project that examined a period of very rapid change in the relationship between the government and the media in Vietnam, in the post-Doi Moi period. It examined case studies from four areas of environmental threat and/or degradation and each case study revealed differences in the relationship between the media and the government. The four case studies were Vedan industrial pollution, bauxite mining in the mountains, de-forestation and climate change. It examined examples of journalism about these areas from the same four major national media outlets as above, namely Vietnam Television (VTV), VnExpress, Tuoi Tre newspaper, and Nhan Dan newspaper. 
The media-government relationship in Vietnam is very heterogeneous and dynamic. The relationship is becoming more flexible but there are also internal contradictions. The key factor in the variation among stories and outlets is the existence of unity or division in government on the political ramifications of the issue. For example, the unity of the government in the Vedan industrial case enabled the expansion of relative independence in media practice on environmental issues. Tuoi Tre newspaper and VnExpress were able to develop their journalistic capital to forge a level of independent initiative in their practice, which broke the previous mould. It showed a more complex relationship between government and journalists, and dynamic interactions between them. In contrast to government unity in response to Vedan's industrial pollution, the bauxite mining case involved high-level conflict within government over bilateral relations with foreign governments and corporations. In that case journalistic independence was much more circumscribed, although the reporting included publicity for high-profile opponents of the mine. This was significant in the relationship between the media and government because the media outlets rarely voice opposition to the policies of Party and State, even after Doi Moi. In the bauxite mining project, the government outlined clear boundaries for the political movement and journalistic practice. Independent media practice was a challenge to the operation and interests of the government, which stopped giving media agencies the scope to expand their capital by dynamic reporting of political conflict, and so actively inhibited their practice.

Climate change, on the other hand, is a multi-lateral global issue and also a complex problem for a developing economy, affecting the lives of millions people in Vietnam. It requires the involvement of many agents to address the problem, including the government, the UN, foreign government aid programmes, NGOs, business enterprises and the public. As such, it can be seen as a very complex and multi-dimensional issue that requires stakeholders to cooperate, and therefore some degree of open discussion through the media. Climate change has the potential to be the most destructive of all environmental challenges for Vietnam, therefore posing enormous challenges for government policies and journalists.

NGOs and government therefore have a dominant role in this field. They have been working together on climate change since 2008 to help Vietnam develop policies and projects to protect and restore the environment. Oxfam, CARE, RECOFTC, CRS, SNV, EMW, WWF, Challenge to Change and SRD play an important role in providing education and policy experience (CCWG, 2009, p. 3; Reid, 2012) which gives them many advantages in dealing with the government and media. The NGOs earn heteronomous capital through their practice and become a part of the orthodoxy in the political field, which is a new situation for them.

The government is starting to develop an effective policy to mitigate and adapt to climate change. It has issued some important legal frameworks on climate change, including the National Strategy on the Prevention and Disaster 
Reduction, the National Target Programme to Respond to Climate Change, the Decision 380/QD-TTG on the pilot payments for forest environmental services, the National Strategy on Climate Change and the National Programme on REDD + . However, the government does not have detailed plans to mitigate the effects of climate change on different sectors. It would pose a very difficult policy and political challenge if Ho Chi Minh City starts to flood every year and the rising sea levels submerge the Mekong Delta, affecting the fish farms and agriculture. Today, climate change is manifesting as extreme weather events and rising sea levels that could threaten the Mekong delta, but in 30 or 40 years' time, what is Vietnam going to do? It could pose the gravest threat for the country and therefore challenge to government, industry and the media, not to mention civil society. At this time, 'the penny has not dropped'.

The media have not helped people to realise the extent of the problem. The four media agencies remain heavily dependent on government sources of information. Media coverage emphasises the international importance of climate change but does little to link the problem to the national context. This poses a question about journalists' capacity and knowledge about the domestic political-economic context. Journalism needs to increase its capacity in order to have a more effective role. Although VTV and Nhan Dan newspaper played a big role in this case and the government gave them power to expand their capital, their practice is still limited. On this issue, journalists have more freedom to find other important sources, but they have not followed through the implications of this freedom. There is the potential for much more assertive and independent reporting.

Climate change programmes attracted many reports in the media but most of them were descriptive and did not assess the quality or effectiveness of the programmes, as they had done in the Vedan industrial pollution case. They also need to take serious actions to inform Vietnamese people and help them to deal with climate change in future. The media outlets could become big players in this field and affect government policies.

It is very instructive that different environmental problems can prompt variable relationships between the media and government. A developing economy always has to deal with multi-faceted socio-economic challenges and this is why a highly centralised government can give the media power to address some problems. There is a great opportunity for the independent development of the media on the climate change issue.

It is a fact that Vietnam is undergoing very rapid change in the relationship between the government and the media, and this change is not uniform, but varies according to the type of issue and its relation to the power of the government. The media-government situation in Vietnam is therefore variable and dynamic. The relationship is becoming more flexible but there are also many contradictions. The key factor in media coverage in Vietnam is unity or division within the government. 
The study of these matters is revealing because it shows journalism in Vietnam has become much more complex and textured in its relationship with government, which could contribute to new understandings of media development in the context of major economic, social and cultural transition.

\section{References}

Bourdieu, P. (1990). In other words: Essays towards a reflexive sociology. Stanford, CA: Stanford University Press.

Bourdieu, P., \& Wacquant, L. J. D. (1992). An invitation to reflexive sociology. Chicago: University of Chicago Press.

Bourdieu, P. (1998). On television. New York: New Press.

CCBC. (2010). Media strategy on climate change. Hanoi: CCBC.

CCWG. (2009). Project proposal: Capacity building on climate change for civil society organisations. Project submitted to embassy of Finland. NGO Climate Change Working Group, Hanoi, Vietnam.

Copsey, T., Nguyen, Y., \& Pham, P. H. (2013). Vietnam: How the people of Vietnam live with climate change and what communication can do. Retrieved on November 3,2013, from www.asiapacificadapt.net/resource/vietnam-how-people-vietnam-live-climatechange-and-what-communication-can-do

CPV. (2011). Resolution the XI National Congress of Communist Party of Vietnam. Hanoi: Communist Party of Vietnam. Retrieved November 23, 2013, from www.chinhphu.vn/portal/page/portal/chinhphu/NuocCHXHCNVietNam/ThongTinTongHop/noidungvankiendaihoidang? categoryId $=10000716 \&$ articleId $=10038365$.

DARA. (2012). DARA and the climate vulnerable forum: Climate Vulnerability MonitorA guide to the cold calculus of a hot planet. Spain: Estudios Grá cos Europeos, S.A.

Dung, P. H. (2008). Climate change coverage by the Vietnamese media. Retrieved on May 22, 2013, from www.earthjournalism.org

Huong, P.T.T., Ninh, N.H., \& Ngoc, T.T.K. (2009). Impacts of climate change to sustainable development. Retrieved on March 21, 2014, from https://translate.google.com/

McMichael, A.J., Campbell-Lendrum, D.H., Corvalán, C.F., Ebi, K.L., Githeko,A.K., Scheraga, J.D., \& Woodward, A. (2003). Climate change and human health: Risks and responses. Geneva, Switzerland: WHO. Retrieved from www.who.int/globalchange/publications/ climchange.pdf

MONRE. (2012). Announcement on the conclusion of the minister Cao Duc Phat briefings on the work of August and tasks implemented in September 2012 by the Ministry of Agriculture and Rural Development. (4341/TB-BNN-VP). Vietnam: Ministry of Agriculture and Rural Development Retrieved on February 21, 2014, from http:// thuvienphapluat.vn/van-ban/Linh-vuc-khac/Thong-bao-4341-TB-BNN-VP-y-kien-ketluan-cua-Bo-truong-Cao-Duc-Phat-tai-cuoc-hop-147350.aspx.

Nash, C. (2016). What is Journalism? The art and politics of a rupture. London: Palgrave Macmillan.

OXFAM. (2014). Harmless harvest: How sustainable agriculture can help ASEAN countries adapt to a changing climate. OXFAM.

Pham, B. D. (2017). The changing relationship between the government and the media in Vietnam with respect to reporting on the environment in the period 2000-2013. Unpublished doctoral thesis, Monash University, Melbourne, Vic., Australia. DOI: 10.4225/03/58A29DoBCC5B2 
Prime Minister. (2008). Approve the national target programme to cope with climate change. (158/2008/QĐ-TTg). Hanoi: Government. Retrieved on May 24, 2014, from http:// thuvienphapluat.vn/van-ban/Tai-nguyen-Moi-truong/Quyet-dinh-158-2008-QD-TTGphe-duyet-Chuong-trinh-muc-tieu-quoc-gia-ung-pho-voi-bien-doi-khi-hau-82256.aspx.

RECOFTC. (2014). Community forestry adaptation roadmap to 2020 for Vietnam. Available online: http://rightslinklao.org/wp-content/uploads/downloads/2014/11/ Vietnam_Maproad_2014OCT01_low-Res.pdf

Reid, J. C. (2008). Rapid assessment of the extent and impact of sea level rise in Viet Nam. (P.-J. Meynell Ed.). Kimdo Design, Hanoi, Viet Nam: ICEM-International Centre for Environmental Management, Indooroopilly, QLD, Australia.

Reid, H., Ampomah, G., Prera, M. I. O., Rabbani, G. \& Zvigadza, S. (2012). Southern voices on climate policy choices. Analysis of and lessons learned from civil society advocacy on climate change. London, UK: International Institute for Environment and Development (IIED).

Sterrett, C. L. (2015). Final evaluation of the climate smart community based disaster risk reduction project in Vietnam. Retrieved on August 11, 2015, from http://reliefweb.int/report/ viet-nam/final-evaluation-climate-smart-community-based-disaster-risk-reduction-project

Thayer, C. A. (2009). Vietnam and the challenge of political civil society. Contemporary Southeast Asia, 31(1), 1-27.

Thuy, P. T., Moeliono, M., Hien, N. T., Tho, N. H., \& Hien, V. T. (2012). The context of REDD + in Vietnam drivers, agents and institutions (CIFOR Ed.). Bogor, Indonesia.: CIFOR.

USAID. (2015). Climate change cooperation. Retrieved on August 15, 2014, from https:// www.usaid.gov/vi/gsearch/

Vien, T. D. (2011). Climate change and its impact on agriculture In Vietnam. ISSAAS, $17(1), 17-21$.

VTV (Writer) \& News and Current Affairs (Director). (2000). Germany: UN Conference on Climate Change and the agreement on the Kyoto Protocol. Germany.

Webb, J., Schirato, T., \& Danaher, G. (2002). Understanding Bourdieu. Sydney, Australia: Allen \& Unwin.

World Bank. (2011). Vulnerability, risk reduction, and adaptation to climate change. Viet Nam: The World Bank Group.

World Bank. (2014). Scaling up rural sanitation, investing in the next generation, children grow taller, and smarter, in rural, mountainous villages of Vietnam where community members use improved sanitation. Retrieved on May 21, 2015, from http://documents. worldbank.org/curated/en/2014/12/23837851/scaling-up-rural-sanitation-investingnext-generation-children-grow-taller-smarter-rural-mountainous-villages-vietnamcommunity-members-use-improved-sanitation

\section{Dr Binh Duong Pham teaches and researches at the Academy of Journalism and Communication in Hanoi, Vietnam. \\ duong_patriker@yahoo.com}

\section{DrChris Nash is Professor of Journalism at Monash University, Melbourne, and is on the editorial board of Pacific Journalism Review.}

